\title{
mMaspin: The Mouse Homolog of a Human Tumor Suppressor Gene Inhibits Mammary Tumor Invasion and Motility
}

\author{
Ming Zhang, Shijie Sheng, Nicolai Maass,* and Ruth Sager \\ Dana Farber Cancer Institute, Harvard Medical School, Boston, \\ Massachusetts, U.S.A.
}

\begin{abstract}
Background: The human maspin gene encodes a protein in the serine proteinase inhibitor (serpin) family with tumor-suppressing functions in cell culture and in nude mice. In order to examine the role of maspin in an intact mammal, we cloned and sequenced the cDNA of mouse maspin. The recombinant protein was produced and its activity in cell culture was assessed.

Materials and Methods: Mouse maspin (mMaspin) was cloned by screening a mouse mammary gland cDNA library with the human maspin cDNA probe. Northern blot analysis was used to examine the expression patterns in mouse tissues, mammary epithelial cells, and carcinomas. Recombinant mMaspin protein was produced in E. coli. Invasion and motility assays were used to assess the biological function of mMaspin.

Results: mMaspin is $89 \%$ homologous with human maspin at the amino acid level. Like its human homolog,
\end{abstract}

mMaspin is expressed in normal mouse mammary epithelial cells and down-regulated in mouse breast tumor cell lines. The expression is altered at different developmental stages in mammary gland. Addition of the recombinant mMaspin protein to mouse tumor cells was shown to inhibit invasion in a dose-dependent manner. As with the human protein, recombinant mMaspin protein also inhibited mouse mammary tumor motility. Deletion in the putative mMaspin reactive site loop (RSL) region resulted in the loss of its inhibitory functions.

Conclusions: mMaspin is the mouse homolog of a human tumor suppressor gene. The expression of mMaspin is down-regulated in tumor cells and is altered at different developmental stages of mammary gland. mMaspin has inhibitory properties similar to those of human maspin in cell culture, suggesting that the homologous proteins play similar physiological roles in vivo.

\section{INTRODUCTION}

Human maspin was identified as a member of the serine proteinase inhibitor (serpin) superfamily (1). Transfection of tumor cells with maspin cDNA inhibits invasion and motility and decreases tumor growth and metastatic ability in nude mice (1-3). Thus maspin exhibits strong tumor-suppressing activity in biological assays.

The mouse provides a model system for genetic manipulation. The study of maspin in mouse has obvious advantages: (1) hormonal regulation of maspin is very difficult to study in

Address correspondence and reprint requests to: Ruth Sager, Dana Farber Cancer Institute, 44 Binney Street, Boston, MA 02115, U.S.A.

*Current address: Dept. of Obstetrics and Gynecology, University Hospital of Kiel, 24105 Kiel, Germany. human, whereas it is easy to obtain samples from mouse mammary glands at different developmental stages; (2) transgenic animals can be produced to study the effects of overexpression of maspin on mammary gland development and tumor inhibition; and (3) knock-out mice can be produced to study the loss of function of maspin. As an initial study, we have shown that expression of mouse maspin (mMaspin) is regulated at different stages of mammary gland development, indicating that the gene responds to hormonal regulation.

Structurally, the maspin protein is an unusual serpin. It is unclear whether the molecule acts as a protease inhibitor or by another mechanism $(2,4,5)$. The protein lacks a typical secretory sequence and has not been detected in the 
media of cultured cells. Instead, the protein is found in the membrane fraction as well as in the cytosol of normal human mammary epithelial cells by cell fractionation and by immunostaining (3).

This paper reports the sequence of the homologous mouse maspin and compares its sequence and functional activity to those of the human recombinant protein. Initially, mouse maspin was cloned and sequenced for its use in producing transgenic and knockout mice. We provide evidence of a strong sequence similarity between mouse and human proteins, similarity of expression in particular tissues, and similar functional activity of the recombinant mouse protein in invasion and motility assays.

Together, these data demonstrate the validity of using mouse maspin for studying the physiological activities of maspin in the intact organism. In addition, sequence comparisons may provide clues to structure-function relationships of this molecule.

\section{MATERIALS AND METHODS \\ Cell Culture}

Normal mouse mammary epithelial cell lines HC11 (from Dr. David Salomon, NIH, Bethsda, MD) and NMuMG (ATCC, Rockville, MD) were grown in D-MEM medium supplemented with $10 \%$ fetal calf serum (FCS), $10 \mathrm{ng} / \mathrm{ml} \mathrm{EGF}$, and $10 \mathrm{mg} / \mathrm{ml}$ insulin. Mouse mammary tumor cell lines CSMLO (low invasive) and CSML100 (high invasive) (both from Dr. Sayeeda Zain, University of Rochester, NY) were grown in D-MEM medium supplemented with $10 \%$ FCS.

\section{Isolation of cDNA Clones}

Mouse mammary cDNA library was obtained from Dr. Robert Friis (University of Bern, Bern, Switzerland). Recombinant phages from the library were plated at a density of $2 \times 10^{3} \mathrm{pfu} /$ 150-mm diameter dish on E. coli XL1-blue. Forty duplicate replica filters were prepared from the library and hybridized with ${ }^{32} \mathrm{P}$-labeled human $2.6 \mathrm{~kb}$ maspin cDNA probe, in the hybridization solution containing $50 \%$ formamide, $2 \times$ SSC, $5 \times$ Denhardt's solution, $0.1 \%$ sodium pyrophosphate, $0.2 \%$ SDS, and $300 \mathrm{mg} / \mathrm{ml}$ samon sperm DNA. The filters were washed twice at room temperature for $30 \mathrm{~min}$ each in $2 \times$ SSC with $0.2 \%$ SDS followed by a 30 -min wash with
$0.1 \times \mathrm{SSC}, 0.1 \%$ SDS at $37^{\circ} \mathrm{C}$, and another wash at $50^{\circ} \mathrm{C}$. After autoradiography, the positive plaques were picked and rescreened with the same procedure until a pure plaque was isolated. Inserts were sequenced to confirm the presence of mouse maspin cDNA.

\section{Northern Blot Analysis}

For mouse tissue Northern analysis, $10 \mathrm{mg}$ of total RNAs from different mouse tissue organs were used (kindly provided by Dr. Florence Botteri, Friedrich Miescher Institute, Basel, Switzerland). RNA from cultured cells was prepared as described (6). Total RNA was fractionated on $1 \%$ agarose-1.7 $\mathrm{M}$ formaldehyde gels, transferred to Zetaprobe (Bio-Rad) membrane in $20 \times$ SSC, and baked for $1 \mathrm{hr}$ at $80^{\circ} \mathrm{C}$. Blots were probed with a $1.5 \mathrm{~kb}$ EcoRl/Xhol fragment from the mouse maspin cDNA plasmid. 36B4 was used as an internal loading and transfer control (7).

\section{Construction of pGST-mMaspin and pGST-mMaspin $\triangle R S L$ Vectors}

The mMaspin coding region was amplified by polymerase chain reaction (PCR) for 25 thermal cycles using a standard protocol (8) (see Fig. 8). The $5^{\prime}$-primer is $5^{\prime}$-GGTACCGGATCCATGGA TGCCCTGAGACTGGCA- $3^{\prime}$. The $3^{\prime}$-primer is $5^{\prime}$ TCCCCCGGGTCGACTACAGACAAGTTCCCTGA GA- $3^{\prime}$. The PCR product was digested with BamHl and Smal and ligated to pGEX-2T vector that has been linealized by BamH1/Smal double digestions. The ligation mixtures were used to transform XL-1 blue cells. Ampicillin-resistant transformants were screened by colony hybridization using ${ }^{32}$ p-labeled mMaspin insert as a probe. The nucleotide fidelity of the PCR-produced maspin was confirmed by sequencing. The new construct was designated pGST-mMaspin.

To delete the RSL region of mMaspin, a DNA fragment encoding part of the RSL region and the C-terminus was deleted by EcoR 1 digestion. One of the EcoRl sites is located at the $1108 \mathrm{nt}$ which corresponds to the $\mathrm{P}^{\prime}$ site of RSL at the amino acid level. The other EcoR 1 site is located in the vector. Digestion by EcoRl enzyme removed the smaller EcoRl/EcoRl insert by gel purification. The remaining portion was ligated and transformed into XLl-blue cells. The new construct was designated as pGST-mMaspin $\Delta$ RSL (see Fig. 6). 


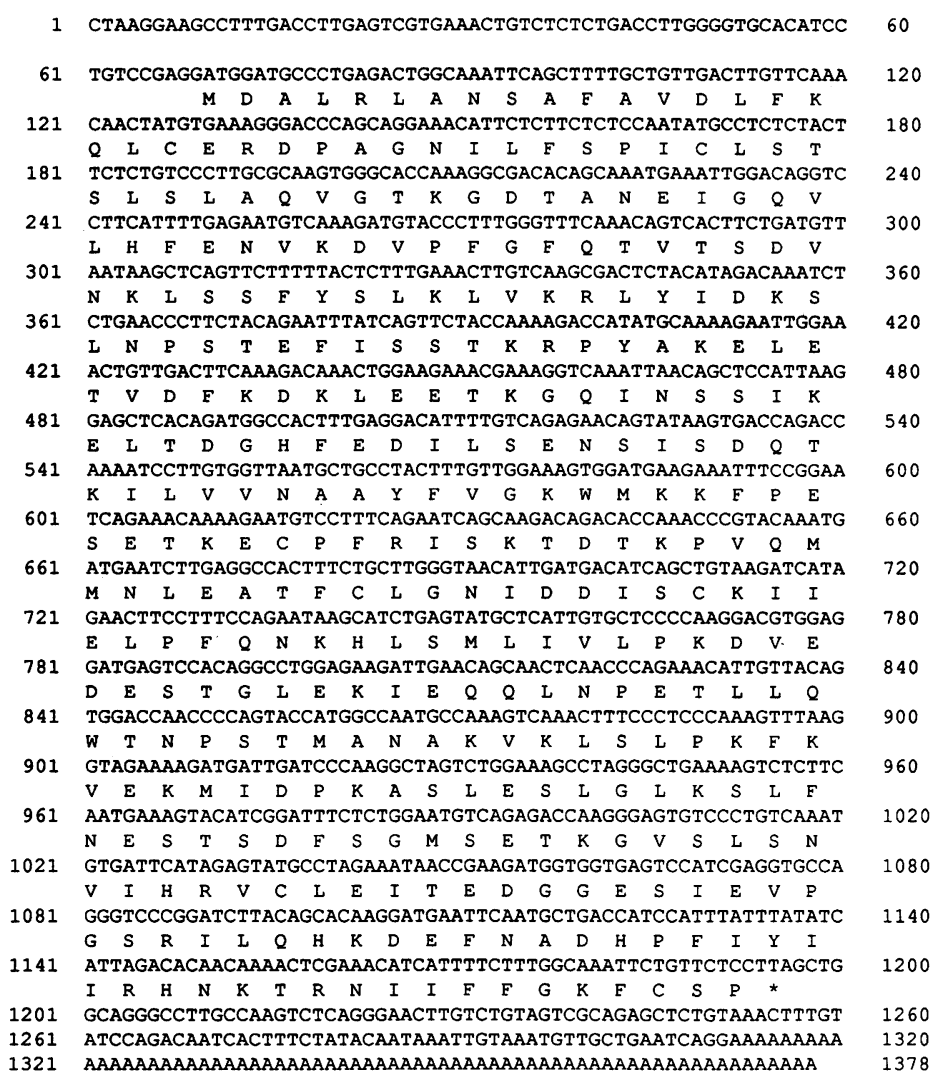

\section{Production and Purification of Recombinant GST-mMaspin and GST-mMaspin $\Delta R S L$}

E. coli XLl-blue transformed by pGST-mMaspin and pGST-mMaspin $\triangle$ RSL were grown in LBA medium until the $\mathrm{OD}_{600}$ value of the culture reached 0.8-1.0. Isopropyl-b-D-thiogalactopyranoside (IPTG) was added to a final concentration of $0.2 \mathrm{mM}$. The bacteria were harvested after another hour of incubation at $37^{\circ} \mathrm{C}$ with vigorous shaking. The purification of GST fusion proteins was carried out as described by Smith and Johnson (9). The sizes of both fusion proteins were confirmed by SDS-PAGE gel eletrophoresis and western analysis.

\section{Western Blot Analysis}

The mouse mammary cells were lysed in electrophoresis sample buffer, and the extracts were subjected to electrophoresis on a 10\% SDS-polyacrylamide gel and transferred to Immobilon membrane. The mMaspin was detected by antibody AbS3A (1) with the ECL (enhanced chemiluminescence) system (Amersham).
FIG. 1. Nucleotide and deduced amino acid sequences of the mMaspin cDNA

ATG starts at $69 \mathrm{bp}$. The gene bank accession number is U54705.

\section{In Vitro Invasion Assay Using Membrane Invasion Culture System (MICS) and Reconstituted Basement Membrance (Matrigel)}

Ten mM polycarbonate membranes were coated with $4 \mathrm{mg} / \mathrm{ml}$ growth factor-reduced matrigel in DFCI-1 medium as described by Hendrix (10) and Sheng (3) with some modifications. The cells were seeded at a density of 50,000 cells $/ \mathrm{ml} /$ well in DFCI-1 medium. Recombinant mMaspin and its mutant were added as indicated in Figure 7. After incubation at $37^{\circ} \mathrm{C}$ with $6.5 \% \mathrm{CO}_{2}$ for 48 $\mathrm{hr}$, the medium plus the cells were removed from the bottom chambers and concentrated on 3-mM polycarbonate membranes using a Minifold 1 apparatus (Schleicher and Schuell, Keene, $\mathrm{NH})$. A LeukoStat staining kit from Fisher was used to fix and stain the cells, which were counted using a Carl Zeiss microscope.

\section{In Vitro Motility Assays}

Motility assays were performed as described by Hendrix (10) and Sheng (3) with some modifi- 


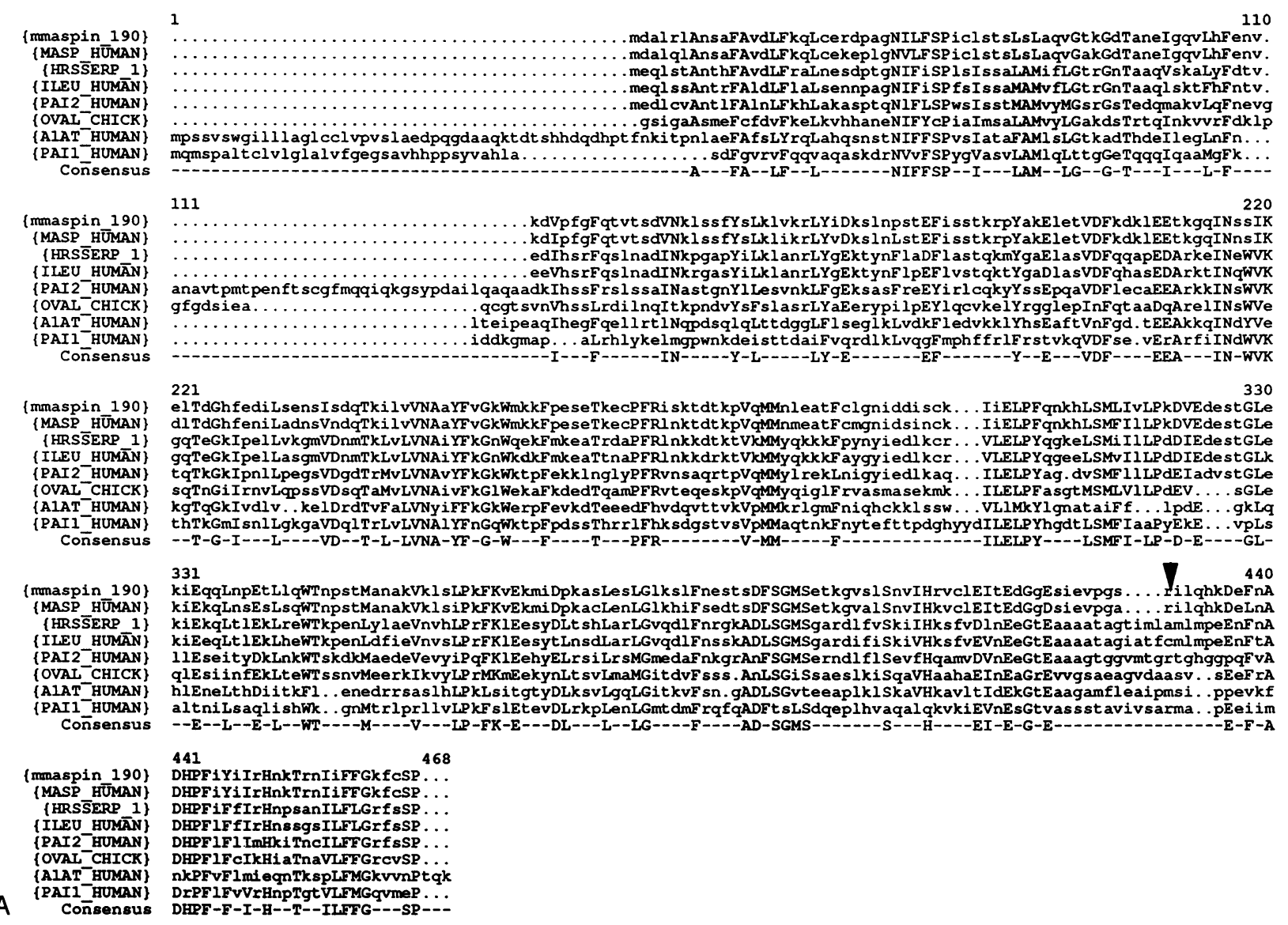

\section{FIG. 2A. Comparison of maspin amino acid sequence with those of other serpins}

Comparison was run using the GCG program (Genetics Computer Group, Inc., Madison, Wisconsin). Highly conserved residues (from at least 6 out of 8 species) are indicated in the capital case. Row 1, mouse mMaspin (mmaspin_190); row 2, human maspin (MASP_HUMAN); row 3, horse serapin (HRSSERP_1); row 4, human monocyte-neutrophil elastase inhibitor (ILEU_HUMAN); row 5, plasminogen activator inhibitor type 2 (PAI2_HUMAN); row 6, chicken ovalbumin (OVAL_CHICK); row 7, human al-antitrypsin (AlAT_HUMAN); row 8, human plasminogen activator inhibitor type 1 (PAIl_HUMAN). Arrows denote the putative reactive center site for mMaspin and other serpins.

cations. Briefly, the bottom wells of the MICS (membrane invasion culture system) apparatus were filled with DFCI-1 medium. Polycarbonate membrane of $10-\mu \mathrm{m}$ pore size (Poretics, Livermore, CA) was precoated with $50 \mu \mathrm{g} / \mathrm{ml}$ growth factor-reduced matrigel (Collaborative Biomedical Products, Bedford, MA) and assembled into the MICS apparatus. Triplicates of 50,000 cells in $1 \mathrm{ml}$ of DFCI-1 medium were seeded into the top wells of the MICS chamber in a random fashion. The cell culture was incubated at $37^{\circ} \mathrm{C}$ in a humidified incubator with $6.5 \% \mathrm{CO}_{2}$ for $5 \mathrm{l} / 2 \mathrm{hr}$. Cells in the bottom wells were harvested and counted as described $(3,11)$.

\section{RESULTS}

\section{mMaspin Is Highly Homologous to Human Maspin}

Mouse maspin cDNA was isolated from a mouse mammary gland cDNA library using human maspin cDNA as a probe. Two positive clones were identified out of $10^{5}$ clones. To obtain fulllength cDNA, the same library was rescreened with the cDNA fragment from one of the positive clones as a probe. Twelve new positive clones were identified and sequenced. The longest cDNA sequence contained $1378 \mathrm{bp}$, including $69 \mathrm{bp} \mathrm{5}$ untranslated region, $1128 \mathrm{bp}$ in the 


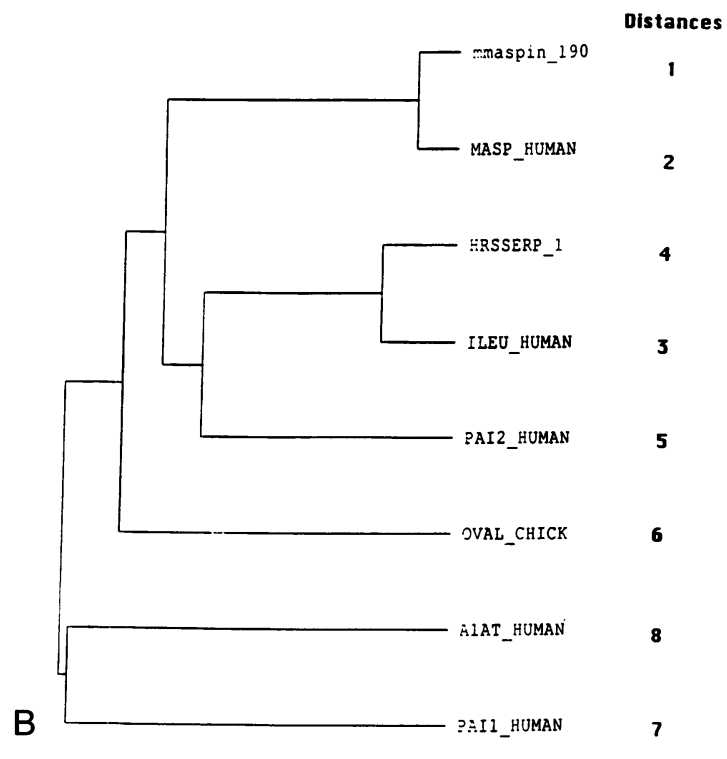

FIG. 2B. Evolutionary comparison of mMaspin with most homologous serpins

The figure was plotted using the pileup program of GCG (Genetics Computer Group, Inc., Madison, Wisconsin). Distances between mMaspin and other serpins were determined by the distance program of GCG. Notations are the same as in Fig. 2A.

coding region, and $181 \mathrm{bp}$ in the $3^{\prime}$-untranslated region. The poly(A) was added $23 \mathrm{bp}$ after the polyadenylation signal site (Fig. 1).

The deduced amino acid sequence of mMaspin has $89 \%$ homology with its human counterpart. The high similarity demonstrates that the cloned cDNA is most likely the mouse homolog of human maspin. In addition, a major difference in the mRNA lies in the $3^{\prime}$ untranslated region. mMaspin cDNA has a short $3^{\prime}$-UTR, compared with the $1.2 \mathrm{~kb} 3^{\prime}$-UTR in the human maspin CDNA (1).

\section{mMaspin Belongs to the Serpin Gene Family}

mMaspin is closely related to members of the serpin superfamily (Fig. 2A). The degree of homology at the amino acid level is as follows: human maspin, $89 \%$; horse serapin, $42 \%$; human monocyte-neutrophil elastase inhibitor, $36 \%$; human PAI2, 33\%; chicken ovalbumin, $31 \%$. The phylogenetic tree in Fig. 2B shows the conservation between mouse mMaspin and other serpins.

An important feature of serpins is the presence of the reactive site loop or RSL. The Pl residue, $\mathrm{N}$-terminal to the cleavage site of the reactive center, plays an important role in determining target specificity. Serpins with Ala, Val, or Met as Pl residues inhibit elastase-like proteases, whereas serpins with Arg at the P1 position inhibit trypsin-like proteases $(12,13)$. Human maspin has an Arg at the Pl site (1). Comparison of mouse and human maspin in both primary structure and on a three-dimensional model based on ovalbumin (not shown) strongly suggests the presence of an Arg at the Pl site of mMaspin. Thus, mouse and human maspin may have the same or similar targets.

\section{Expression of mMaspin in Mouse Tissues}

Northern blot analysis was carried out using total RNA from different mouse tissues (Fig. 3). The mammary gland has the highest level of expression. mMaspin is also expressed in large intestine, skin, tongue, and stomach, and weakly expressed in other tissues such as lung and thymus. Multiple transcripts were identified. In the mammary gland, the smallest transcript $(1.5 \mathrm{~kb})$ matches the full-length cDNA.

The mammary gland undergoes most of its morphogenetic and functional changes postnatally, under hormonal and growth factor control $(14,15)$. Expression of mMaspin is regulated in this process. We have observed a low level of expression of mMaspin in the mammary gland from prepuberty, virgin mice (Fig. 3, lane MG5), when the mammary gland is not fully developed and steroid hormones are at a relative low level. In lactating stages (Fig. 3, lanes MGl-4), mMaspin is dramatically elevated, demonstrating that mMaspin expression links to mouse mammary gland differentiation.

To compare the expression patterns of mouse and human tissues, Northern blot analysis with human tissue RNAs and human cDNA probe was carried out and the results compared with those of mouse tissue blots hybridized with mouse maspin cDNA. As shown in Table 1, the human maspin expression patterns match well those of mMaspin.

\section{Down-regulation of mMaspin in Mouse Mammary Tumor Cells}

We have reported previously the loss of expression of human maspin in mammary carcinomas (1). To examine the expression pattern of mMaspin in mouse mammary epithelial cells, we performed a Northern analysis with RNA isolated 

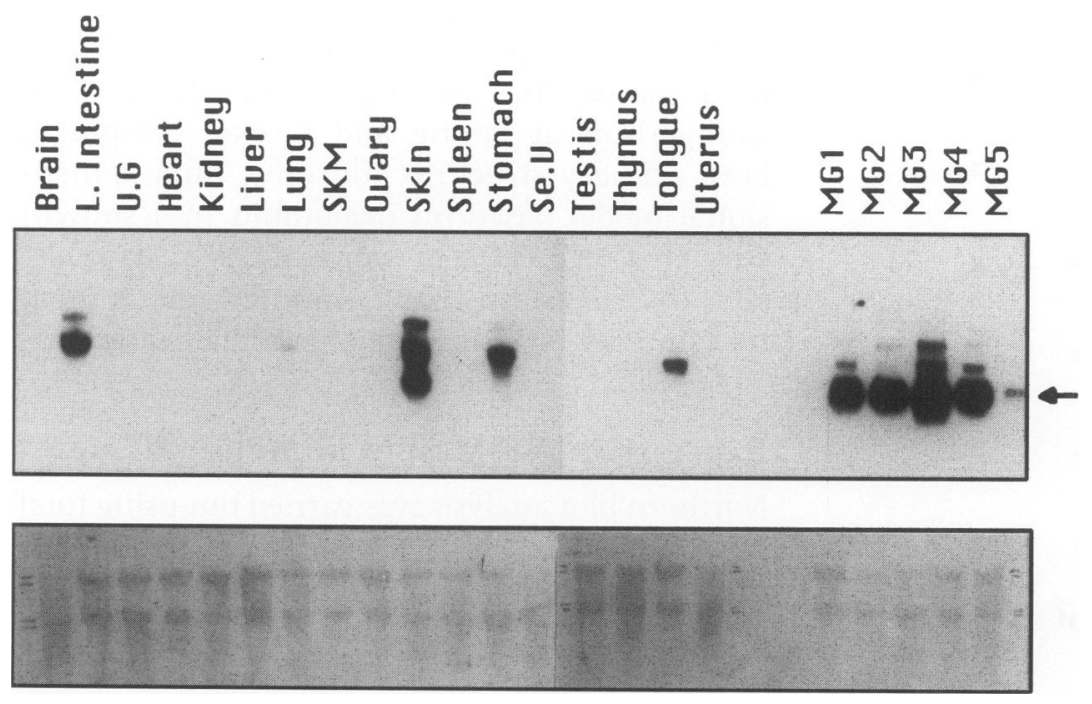

FIG. 3. Northern analysis of mMaspin in mouse tissues

Each lane contains $10 \mu \mathrm{g}$ of total RNAs. The blots were hybridized with full-length mMaspin cDNA probe. The smallest transcript (indicated by arrow) has a size of $1.5 \mathrm{~kb}$. The $28 \mathrm{~S}$ and $18 \mathrm{~S}$ RNAs were stained by methylene blue and served as the loading control. L. Intestine, large intestine; U.G, upper gut or small intestine; SKM, skeletal muscle; Se.V, seminal vesicle; MGl, mammary gland from a female breast-feeding newborns 1 day old; MG2, mammary gland from a female breast-feeding newborns 7 days of age; MG3, mammary gland from a female breastfeeding newborns 15 days of age; MG4, mammary gland from a female breast-feeding newborns 16 days of age; MG5, mammary gland from a prepuberty 16-day-old female. from several mouse cell lines (Fig. 4). mMaspin is expressed at a high level in mouse normal mammary epithelial cells (NMuMG, HC11). The level of expression is down-regulated in low-invasive mouse mammary tumor cells (CSML0) and lost in a highly invasive tumor cell line (CSML100).

To verify that the levels of RNAs reflect those of protein, we carried out a Western blot analysis using AbS3A polyclonal antiserum raised against the S3A region of human maspin (1) (Fig. 5). mMaspin has a $100 \%$ similarity with human maspin in the S3A region (Fig. 2). The high homology of this region and overall structure similarity between these two molecules allowed cross-reaction between mMaspin and AbS3A. As shown in Fig. 5, mMaspin can be easily detected in NMuMG normal mouse mammary epithelial cells, it is decreased in CSMLO tumor cells, and it is not detectable in CSML100 tumor cells.

Thus, mMaspin is down-regulated in our mouse mammary tumor cell lines at both the RNA and protein levels.

\section{Production of Recombinant mMaspin Proteins}

Recombinant mMaspin proteins were produced in $E$. coli using the vector pGST-mMaspin and its derivative as shown in Fig. 6 . The fusion protein contains two polypeptides covalently linked by a thrombin cleavage site plus a short sequence resulting from BamHl/Smal ligation. The mutant mMaspin construct was produced by deletion of an EcoR1/EcoRl fragment in the pGST-mMaspin vector.

The fusion proteins were induced by IPTG (Fig. 7). As shown in Fig. 7, GST-mMaspin, whose molecular weight $(67 \mathrm{kd})$ corresponds to the total size of mMaspin $(42 \mathrm{kd})$ and GST $(25 \mathrm{kd})$, was induced $\mathrm{l} \mathrm{hr}$ after the addition of IPTG. No significant increase of yield was noticed after longer $(2 \mathrm{hr})$ induction. Using a glutathionine affinity column, the GST-mMaspin was purified to nearly $100 \%$ homogeneity in a single step. The identity of purified GST-mMaspin was confirmed by Western blotting using the AbS3A antibody (data not shown).

\section{mMaspin Functions to Block Tumor Invasion and Inhibit Tumor Cell Motility}

The biological function of recombinant mMaspin was investigated with MICS invasion and motility assays $(3,11)$. A pair of mouse mammary tumor cells, CSMLO and CSML100, which are well characterized for their invasiveness $(16,17)$, were used in both assays. Normally, about $10 \%$ of the low-invasive CSML0 cells and $32 \%$ of the high-invasive CSML100 cells seeded in the upper 
TABLE 1. Tissue expression patterns of human and mouse maspin

\begin{tabular}{lcc}
\hline Tissues & Human & Mouse \\
\hline Mammary gland & + & + \\
Brain & - & - \\
Large intestine & ND & + \\
Small intestine & + & + \\
Heart & - & - \\
Kidney & - & - \\
Liver & - & - \\
Lung & - & - \\
Ovary & - & - \\
Pancreas & - & ND \\
Placenta & - & ND \\
Prostate & + & ND \\
Seminal vesicle & ND & - \\
Skeletal muscle & - & - \\
Skin & + & + \\
Spleen & - & - \\
Stomach & ND & + \\
Thymus & + & + \\
Tongue & ND & + \\
Uterus & ND & \\
\hline & & + \\
\hline
\end{tabular}

Northern blot analysis of human and mouse maspin mRNA in tissues. Human maspin cDNA was ${ }^{32} \mathrm{P}$-labeled to probe human tissue blots (tissue blots from Clontech, Inc., Palo Alto, CA). The mouse mMaspin cDNA was ${ }^{32} \mathrm{P}$-labeled to probe mouse tissue blot (used in Fig. 3.). Both results are summarized in the table. (+) indicates positive expression; $(-)$ indicates no expression. ND, not done.

chamber invade the reconstituted basement membrane. Addition of mMaspin to the cell culture inhibits the invasion by both CSMLO and CSML100 cells (Fig. 8). This inhibition increases as the concentration of GST-mMaspin increases. The highest amount of inhibition, achieved with a concentration of $1.2 \mu \mathrm{M}$, was about $60 \%$ for CSMLO cells (from $10 \%$ to $4 \%$ ) and $62 \%$ for CSML100 cells (from $62 \%$ to $12.5 \%$ ).

For the motility assay, the recombinant proteins were added at different dosages to CSMLO and CSML100 cell suspensions and incubated with cells for $30 \mathrm{~min}$ at room temperature before seeding. Under control conditions, 5.8\% CSMLO cells and $7.2 \%$ CSML100 cells move through the $10-\mu \mathrm{M}$ polycarbonate membrane. Addition of GST-mMaspin inhibits the motility of both CSMLO and CSML100 cells (Fig. 9). The highest

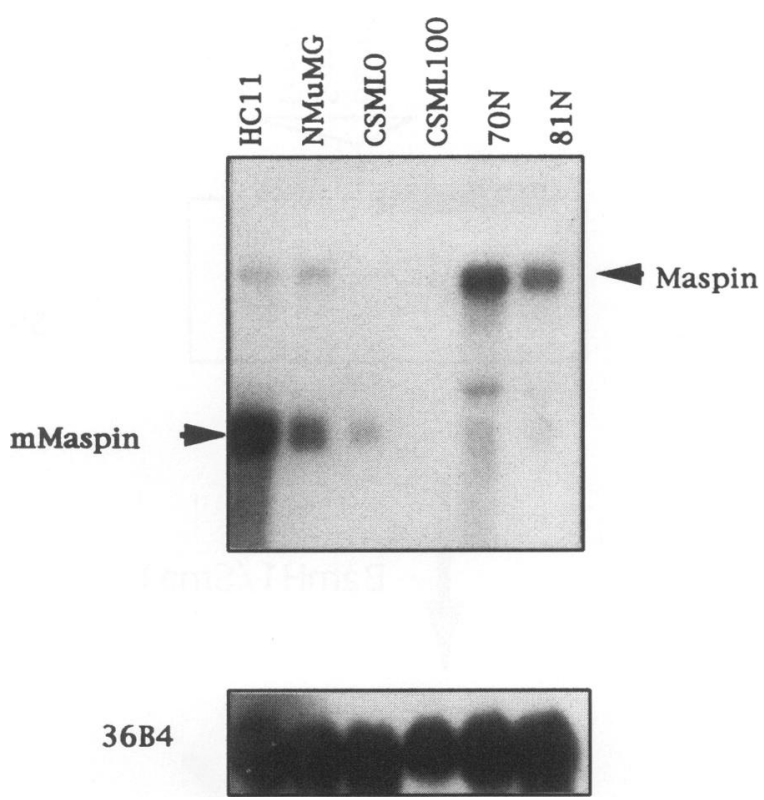

FIG. 4. Northern analysis of mMaspin mouse normal mammary epithelial cells and carcinomas

HC11 and NMuMG are two mouse normal mammary epithelial cell lines. CSMLO is a mouse mammary low-invasive adenocarcinoma cell line. CSML100 is a mouse mammary highly invasive epithelial cell line. Each lane contains $20 \mu \mathrm{g}$ of total RNA. The blot was hybridized with $1.5 \mathrm{~kb}$ mMaspin cDNA probe. mMaspin cDNA was cross-hybridized with human maspin mRNA from two human normal mammary epithelial cells 70N and 81N. 36B4 was used as loading control.

inhibitions at the concentration of $1.2 \mu \mathrm{M}$ were about $78 \%$ for CSMLO cells (from $5.9 \%$ to $1.25 \%$ ) and $80 \%$ for CSML100 cells (from $7.2 \%$ to $1.4 \%$ ).

The reactive site loop (RSL) is the key do-

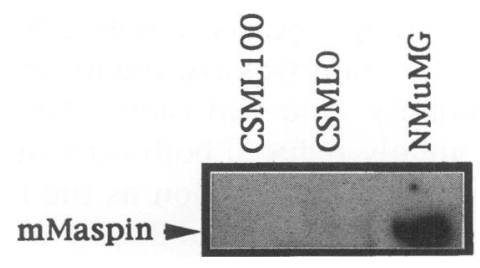

FIG. 5. Western blot analysis of mMaspin in mouse mammary epithelial cells

Description of cells is the same as in Fig. 4. A total of $100 \mu \mathrm{g}$ of protein extract was loaded for each lane. mMaspin (arrow) has a size of $42 \mathrm{kd}$. mMaspin was detected by antibody AbS3A with ECL system (Amersham). 

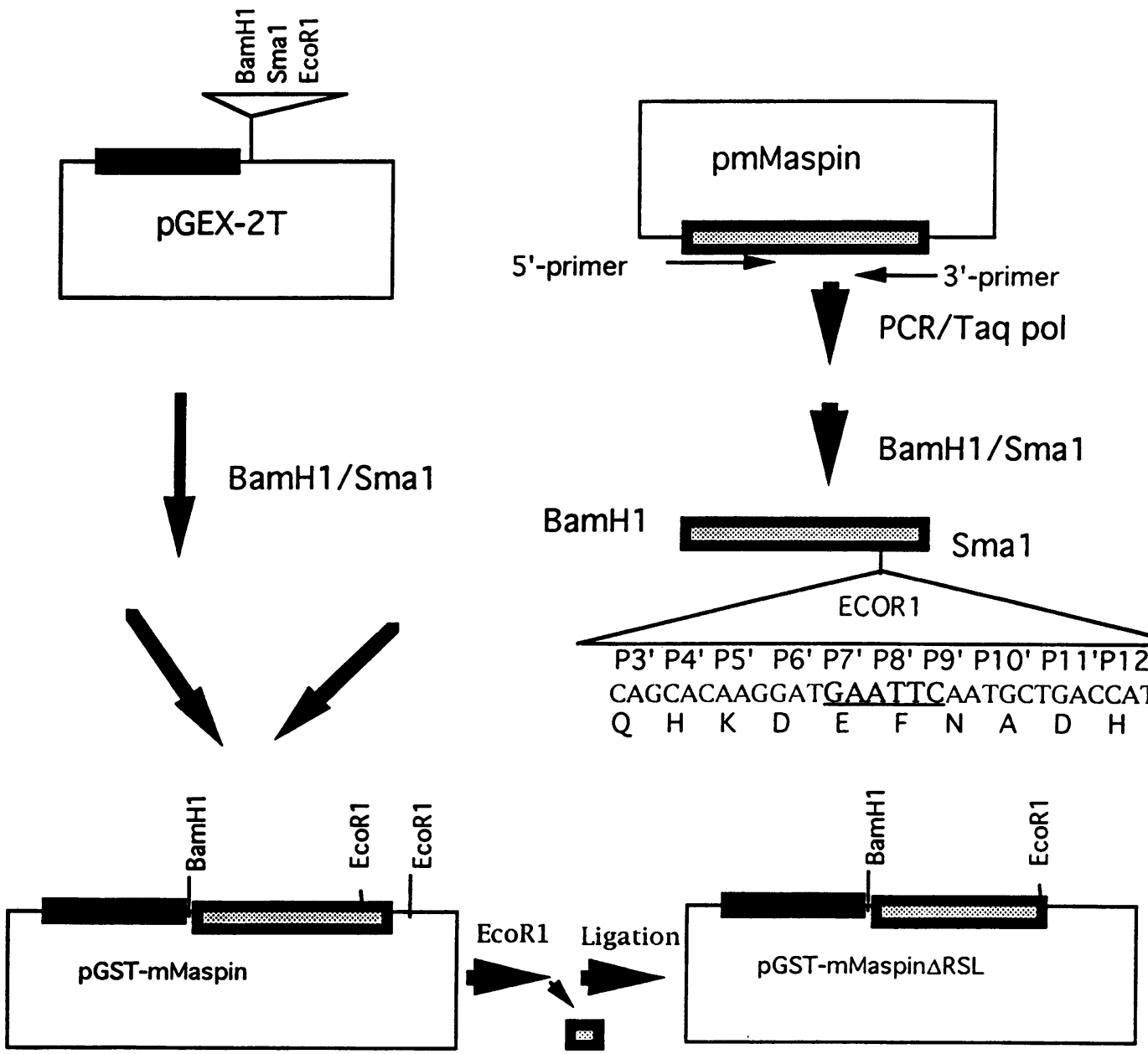

FIG. 6. Construction of pGST-mMaspin and pGST-mMaspin $\Delta R S L$

The nucleotide and amino acid sequences in the putative RSL region are illustrated. The EcoR 1 site is underlined.

main responsible for the function of inhibitory serpins. We constructed a mutated mMaspin (GST-mMaspin $\Delta$ RSL) by deleting a C-terminal region containing a partial putative RSL region (Fig. 6). The mutant was assayed for its ability to inhibit motility and invasion. Mutation of mMaspin greatly reduced both activities, identifying the putative RSL region as the functional domain involved in the inhibition of invasion and motility (Figs. 8, 9).

These data have demonstrated that mMaspin functions to inhibit mouse mammary tumor cell invasion and motility, just as human maspin inhibits human mammary carcinoma cells, suggesting that mMaspin and its human homolog play similar physiological roles in vivo.

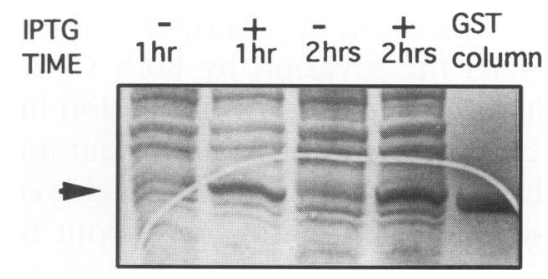

FIG. 7. The expression and purification of mMaspin revealed by SDS-PAGE followed by standard Coormassie Briliant Blue R-250 staining

Each lane (except lane 5) contains $20 \mu \mathrm{g}$ of the total proteins extracted from bacteria XLl-blue transformed by PGST-mMaspin in lysis buffer containing $1 \%$ Triton X-100. Cells were grown for $1-2 \mathrm{hr}$ with or without IPTG $(0.2 \mathrm{mM})$. The GST-mMaspin fusion protein has a size of $67 \mathrm{kd}$. Lane $5,1 \mu \mathrm{g}$ of affinity purified GST-mMaspin. 


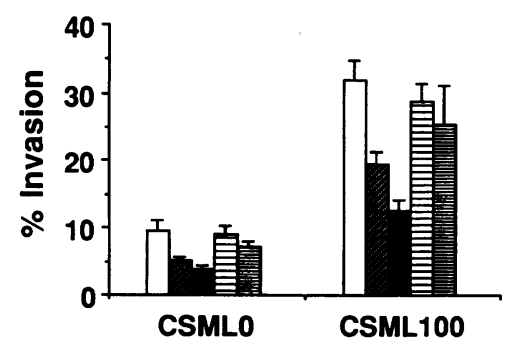

FIG. 8. The effects of GST-mMaspin and GSTmMaspin $\triangle R S L$ on the invasion by two mouse mammary tumor cell lines, CSMLO and CSML100

( $\square)$, untreated cells; ( $/ 4$ ), GST-mMaspin added to cell culture at a final concentration of $0.6 \mu \mathrm{M}$; $(\square)$, GST-mMaspin at the concentration of $1.2 \mu \mathrm{M}$; (周), GST-mMaspin $\Delta$ RSL at the concentration of $0.6 \mu \mathrm{M}$; (冒), GST-mMaspin $\Delta$ RSL at the concentration of $1.2 \mu \mathrm{M}$. Each value represents the average from two independent assays. In each assay, protein samples were added in triplicate. Error bars represent standard error of the means.

\section{DISCUSSION}

We have cloned the full-length cDNA of mMaspin. We consider it to be the mouse homolog of human maspin for the following reasons: (1) a computer search established a high identity between mouse and human DNA and amino acid sequences, indicating their conservation in evolution; (2) the ATG translation initiation codon is located in the same position as the initiation codons of related serpins; and (3) an antibody against the S3A and S4A region of human maspin recognizes mMaspin, indicating conservation not only of amino acid sequence but also of protein structure.

The mammary gland is one of the few mammalian organs that undergoes major morphological and functional changes after birth (18). Before puberty, primitive epithelial ducts develop with few branches. Ductal development is controlled by systemic hormones and local growth and differentiation factors acting on both epithelial and mesenchymal components of the gland $(19,20)$. At pregnancy, rapid epithelial cell proliferation begins with the budding of multiple alveoli from the ducts, which form the functional units of milk production at lactation. After weaning, the gland undergoes massive remodeling, resulting in regression (involution), probably by an apoptotic mechanism. We have demonstrated that mMaspin is highly expressed in the mouse mammary gland. The expression is regulated at

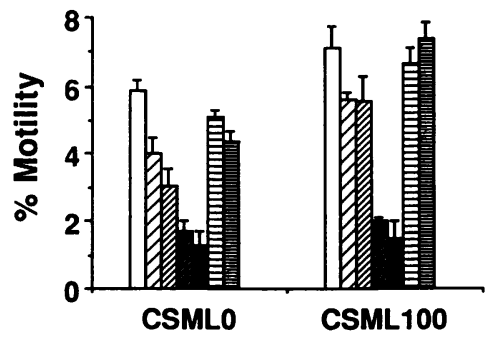

FIG. 9. Effect of mouse mMaspin fusion protein on the motility by two mouse mammary tumor cell lines, CSMLO and CSML100

( $\square)$, untreated cells; ( $\square)$, GST-mMaspin added to cell culture at a final concentration of $0.15 \mu \mathrm{M}$; (囚), GST-mMaspin at the concentration of $0.3 \mu \mathrm{M} ;(\mathbb{Z})$, GST-mMaspin at the concentration of $0.6 \mu \mathrm{M} ;(\square)$, GST-mMaspin at the concentration of $1.2 \mu \mathrm{M}$; (司), GST-mMaspin $\Delta$ RSL at the concentration of $0.15 \mu \mathrm{M}$; (冒), GST-mMaspin $\Delta$ RSL at the concentration of $0.3 \mu \mathrm{M}$. Each value represents the averages from two independent assays. In each assay, protein samples were added in triplicate. Error bars represent standard error of the means.

postnatal developmental stages (prepuberty and lactation), indicating regulation of mMaspin gene expression by differentiation.

Morphogenesis and involution of the mammary gland are accompanied by extensive extracellular matrix (ECM) remoldeling that is mediated by ECM-degrading proteases $(21-24)$. These protease activities are regulated by protease inhibitors during development and involution as well as in mammary tumor progression. The fact that mMaspin functions to block mammary tumor cell invasion and motility in culture suggests that mMaspin plays an important role in mammary gland morphogenesis and in protecting the integrity of mammary gland structure.

The reactive center site is the functional domain among inhibitory serpins $(13,25)$. The Pl site in the RSL determines the type of substrate. Previously, Sheng et al. demonstrated that a deletion at the $\mathrm{Pl}-\mathrm{Pl}^{\prime}$ site in human maspin abolished the activity of maspin (25). With mMaspin, we have found that this region is important since deletion from $\mathrm{P}^{\prime}$ to the $\mathrm{C}$-terminus resulted in a dramatic decrease in activity.

Our RSL deletion analysis provides useful information for developing a gene knock-out construct. Both the human and mouse genes span about $20 \mathrm{~kb}$ in the chromosome. Thus, it is relatively difficult to knock out all the exons efficiently. Deletion of the RSL region served as a model of an in vitro knock-out. Currently, we 
have sequenced the exon encoding the putative RSL and its flanking region and made the construct intended to delete the RSL domain of the mMaspin gene in mice.

Does mouse maspin have the same function as its human homolog in vivo? Our data provide direct evidence that mouse and human maspin play a similar physiological role. First, tissue expression patterns of mMaspin are very similar to those in human maspin (Table 1). mMaspin is expressed in mouse mammary gland, large intestine, skin, tongue, stomach, lung, and thymus. Human maspin is expressed in human mammary gland, prostate, thymus, skin, small intestine. The similar localization of the homologous molecules in different species supports their functional similarity. Second, both human and mouse maspin are expressed at a high level in normal mammary epithelial cells, but down-regulated in mammary tumors. Third, mMaspin functions to inhibit tumor cell invasion and motility just as human maspin does.

Thus, studying the function of maspin with transgenic and knock-out mice should provide valid insights into its role in normal human breast development and in breast cancers.

\section{ACKNOWLEDGMENTS}

The authors thank Dr. Phil Pemberton (LXR, Inc.) for critical reading of the manuscript. This work was supported in part by an NIH grant (CA61253) to R.S. and an NIH fellowship (5T32-CA 09361-14) to M.Z., and by LXR Biotechnology.

\section{REFERENCES}

1. Zou Z, Anisowicz A, Hendrix MJC, Thor A, Neveu M, Sheng S, Rafidi K, Seftor E, Sager R. (1994) Maspin, a serpin with tumor-suppressing activity in human mammary epithelial cells. Science 263: 526-529.

2. Sager $R$, Sheng $S$, Pemberton $P$, Hendrix MJC. (1995) Maspin, a tumor suppressing serpin. Curr. Top. Microbiol. Immunol. 1: 51-64.

3. Sheng S, Carey J, Seftor AE, Dias L, Hendrix JCM, Sager R. (1996) Maspin acts at the cell membrance to inhibit invasion and motility of mammary and prostate cancer cells. Proc. Natl. Acad. Sci. U.S.A. 93: $11669-11674$.

4. Hopkins P, Whisstock J, Sager R. (1994) Function of maspin. Science 265: 1893-1894.
5. Pemberton $P$, Wong D, Gibson $H$, Kiefer $M$, Fitzpatrick P, Sager R, Barr P. (1995) The tumor suppressor maspin does not undergo the stressed to relaxed transition or inhibit trypsin-like serine proteases. J. Biol. Chem. 270: 15832-15837.

6. Swisshelm K, Ryan K, Lee X, Tsou HC, Peacocke M, Sager R. (1994) Down-regulation of retinoic acid receptor $\beta$ in mammary carcinoma cell lines and its up-regulation in senescing normal mammary epithelial cells. Cell Growth Differ. 5: 133-141.

7. Laborda J. (1991) 36B4 cDNA used as an estradiol-independent mRNA control is the cDNA for human acidic ribosomal phosphoprotein PO. Nucl. Acids Res. 19: 3998.

8. Sambrook J, Fritsch EF, Maniatis $\mathrm{T}$ (ed). (1989) Molecular Cloning: A Laboratory Manual, 2nd ed. Cold Spring Harbor Laborotory, Cold Spring Harbor, NY.

9. Smith DB, Johnson KS. (1988) Single-step purification of polypeptides expressed in Escherichia coli as fusions with glutathione S-transferase. Gene 67: 31-40.

10. Hendrix MJC, Seftor EA, Seftor REB, Fidler IJ. (1987) A simple quantitative assay for studying the invasive potential of high and low human metastatic variants. Cancer Lett. 38: 137-147.

11. Chu YW, Runyan RB, Oshima RG, Hendrix MJC. (1993) Expression of complete keratin filaments in mouse $\mathrm{L}$ cells augments cell migration and invasion. Proc. Natl. Acad. Sci. U.S.A. 90: 4261-4265.

12. Travis J, Guzdek A, Potempa J, Watorek W. (1990) Serpins: Structure and mechanism of action. Biol. Chem. Hoppe Seyler 371: 3-11.

13. Huber R, Carrell RW. (1989) Implications of the three dimensional structure of al-antitrypsin for structure and function of serpins. Biochemistry 28: 8951.

14. Coleman S, Silberstein GB, Daniel CW. (1988) Ductal morphogenesis in the mouse mammary gland: Evidence supporting a role for epidermal growth factor. Dev. Biol. 127: 304-315.

15. Robinson SD, Silberstin A, Roberts K, Flanders K, Daniel CW. (1991) Regulated expression and growth inhibitory effects of transforming factor. Development 113: 867878.

16. Tulchinsky E, Ford HL, Kramerov D, Reshetnyak E, Grigorian M, Zain S, Lukanidin E. (1992) Transcriptional analysis of the mts l gene with specific reference to 5' flank- 
ing sequences. Proc. Natl. Acad. Sci. U.S.A. 89: 9146-9150.

17. Tulchinsky E, Kramerov D, Ford HL, Reshetnyak E, Lukanidin E, Zain S. (1993) Characterization of a positive regulatory element in the mtsl gene. Oncogene 8: 79-86.

18. Sakakura T. (1991) New aspects of stromalparenchyma relations in mammary gland differentiation. Int. Rev. Cytol. 125: 165-202.

19. Imagawa W, Bandyopadhyay GK, Nandi S. (1990) Regulation of mammary epithelial cell growth in mice and rats. Endocr. Rev. 11: 494-523.

20. Snedeker S, Brown C, DiAugustine R. (1991) Expression and functional properties of transforming factor alpha and epidermal growth factor during mouse mammary gland ductal morphogenesis. Proc. Natl. Acad. Sci. U.S.A. 88: 276-280.

21. Lefebvre $O$, Wolf $C$, Limacher J, Hutin $P$, Wendling C, Lemeur $M$, Basset $P$, Rio $M$. (1992) The breast cancer-associated stromely- sis-3 gene is expressed during mouse mammary gland apoptosis. J. Cell Biol. 119: 9971002.

22. Ossowski L, Biegel D, Reich E. (1979) Correlation with involution, hormonal modulation and comparison between normal and neoplastic tissues. Cell 16: 867-878.

23. Talhouk RS, Chin JR, Unemori EN, Werb Z, Bissell MJ. (1991) Proteinases of the mammary gland: developmental regulation in vivo and vectorial secretion in culture. Development 112: 439-449.

24. Talhouk RS, Bissell MJ, Werb Z. (1992) Coordinated expression of extracellular matrixdegrading proteinase and their inhibitors regulate mammary epithelial function during involution. J. Cell Biol. 118: 1271-1282.

25. Sheng S, Pemberton PA, Sager R. (1994) Production, purification, and characterization of recombinant maspin proteins. J. Biol. Chem. 269: 30988-30993.

Communicated by R. Sager. Accepted on October 11, 1996. 